Pereira, A.I.A.; Silva, F.J.L.; Silva-Junior, J.M.. Influência dos cursos de capacitação do Projeto Golfinho Rotador na atuação profissional dos condutores de ecoturismo em Fernando de Noronha (PE): uma contribuição a sustentabilidade turística local. Revista Brasileira de Ecoturismo, São Paulo, v.8, n.1, fev/abr2015, pp.31-58.

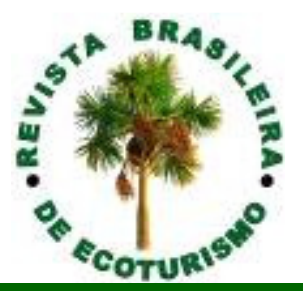

\title{
Influência dos cursos de capacitação do Projeto Golfinho Rotador na atuação profissional dos condutores de ecoturismo em Fernando de Noronha (PE): uma contribuição a sustentabilidade turística local
}

\author{
Development Influence of the training courses of Golfinho \\ Rotador Project in the professional acting of conductors \\ ecotourism in Fernando de Noronha (PE, Brazil): \\ a contribution to tourist sustainability local
}

\author{
Adriana Israel de Almeida Pereira, Flávio José de Lima Silva, \\ José Martins da Silva Júnior
}

\begin{abstract}
RESUMO
Fernando de Noronha é um destino turístico essencialmente propício para a realização do ecoturismo. O condutor desempenha um importante papel nesta atividade. Uma boa formação destes profissionais garante a base necessária para que o turismo desenvolva-se com uma finalidade educativa e ao mesmo tempo contribua para a conservação da localidade. O presente estudo teve como objetivos caracterizar os cursos de formação profissional de condutores de ecoturismo oferecidos pelo Projeto Golfinho Rotador em Fernando de Noronha; identificar o perfil socioeconômico dos condutores; verificar a influência dos cursos de capacitação profissional na atuação dos condutores no Arquipélago; e identificar as percepções dos turistas sobre a atuação dos condutores no Parque Nacional Marinho de Fernando de Noronha (PARNAMAR-FN). Adotou-se como procedimento metodológico uma pesquisa descritiva de abordagem quali-quantitativa, utilizando-se de fontes primárias e secundárias no período de 11 a 22 de junho de 2013 em uma amostra de 56 condutores de ecoturismo cadastrados pelos órgãos gestores da atividade em Fernando de Noronha que realizam atividades com finalidades ecoturísticas e 66 turistas que utilizam os serviços destes profissionais. Os dados foram analisados por meio de estatística descritiva, com elaboração de tabelas de frequência e gráficos. Os resultados mostraram que o perfil dos condutores é formado, em sua maioria, por pessoas do sexo masculino (95\%) com idade superior a 19 anos e inferior a 59 anos de idade, sendo $52 \%$ destes nascidos no Arquipélago de Fernando de Noronha. Os cursos influenciaram desde o aumento da quantidade de condutores na área até o modo de atuar destes profissionais. Dos 56 entrevistados, 30 responderam concordar totalmente que estão presenciando os assuntos abordados e 35 responderam ainda concordar totalmente que estão praticando os conteúdos aprendidos nos cursos no cotidiano. Os turistas mostraramse satisfeitos com o desempenho destes profissionais. Os cursos ofereceram influência positiva na atuação e remuneração destes profissionais, e os condutores foram considerados relevantes para a ocorrência de atividades de ecoturismo na localidade. No presente estudo foi possível verificar que a capacitação profissional realizada pelo Projeto Golfinho Rotador ofereceu importante contribuição para a atuação dos condutores de ecoturismo no PARNAMAR-FN, tanto no que se refere ao aprimoramento dos processos de interpretação dos aspectos ecológicos pelos turistas, como o monitoramento e conservação dos sítios de visitação. Conclui-se também que há um grande interesse da população local em realizar tais cursos, o que tem auxiliado a melhoria da renda destes profissionais, bem como em sua forma de atuação diante da sustentabilidade.
\end{abstract}

PALAVRAS-CHAVE: Ecoturismo; Condutores; Formação Profissional; Fernando de Noronha; Projeto Golfinho Rotador. 


\section{ABSTRACT}

Fernando de Noronha (PE, Brazil) is a tourist destination essentially propitious to the realization of ecotourism. The tour guide plays an important role in this activity. The proper training of these professionals assure that the necessary basis for the development of tourism is settled with an educational purpose and at the same time contributes to local conservation. The present study had as objectives to characterize the professional training courses of ecotourism conductors offered by the Golfinho Rotador Project in Fernando de Noronha; to identify the socio-economic profile of the conductors; to check the influence of professional capacitation courses on acting of the conductores; and to aknowledge the perception of tourists about the work of theirs over the Parque Nacional Marinho de Fernando de Noronha (PARNAMAR-FN). As methodological procedure, it was adopted a descriptive research of qualitative and quantitative approach was adopted as te methodological procedure, using primary and secondary sources from June 11th to the 22nd 2013 in a sample of 56 conductors of ecotourism services registered in management organs of touristic ativities which provide ecotouristic services, as well as with 66 tourists who make use of the services in Fernando de Noronha.. The collected data was analysed by descriptive statistics, that is, by creating frequency tables and graphics. The results show that the profile of conductors is mostly characterized by male sex (95\%) over 19 and under the age of 59 years old and that $52 \%$ of them were born in the Archipelago. The courses influenced to from the increase of workers in the area to their way of working, such that by 56 interviewees, 30 of them totally agreed that they were witnessing all the topics seen in the classroom and 35 confirmed that are practicing the skills learned. The tourists showed to be very pleased with the performance of them. The courses offer a positive influence on their acting and remuneration, and they were considered relevant to the occurrence of ecotourism activities in the locality. This research allowed inferring that the professional training held by Golfinho Rotador Project offer an important contribution to the performance of ecotourism conductors on PARNAMAR-FN, what works not only on the improvement of the interpretation processes of ecological aspects by tourists, such as on monitoring and conservation of visitation places. Concludes too that there a big interest of the local population in perform such courses, this has helped to improve the income of these professionals, as well as its acting on sustentability.

KEYWORDS: Ecotourism; Conductors; Professional Training; Fernando de Noronha; Golfinho Rotador Project

\section{Introdução}

O turismo, com suas mais diversas ramificações, está presente em todos os continentes do mundo, desenvolvendo-se rapidamente e sofrendo constantes mudanças diante de novas exigências dos consumidores. O meio natural tem se tornado um grande foco e o turismo de natureza surge como uma base para o desenvolvimento dessa atividade.

Entretanto, os impactos ocasionados por esse rápido crescimento também são detectados, surgindo assim à necessidade de criar meios de explorar essa atividade sem prejudicar o meio ambiente. Neste contexto surge o Ecoturismo, que é um segmento voltado para a criação de uma consciência ambiental aliada ao desenvolvimento sustentável dos locais onde ocorre.

A educação ambiental advinda das informações abordadas por condutores de ecoturismo capacitados, aliada aos atrativos naturais, dá espaço a uma forte ferramenta no desenvolvimento sustentável do turismo.

O presente estudo abordará a temática do ecoturismo e sua relação com a formação profissional de condutores em unidades de conservação. Neste aspecto foi considerado como foco de estudo a formação dos condutores de ecoturismo cadastrados pelo órgão gestor das unidades de 
conservação de Fernando de Noronha e a percepção dos turistas sobre a atuação destes profissionais.

Fernando de Noronha é um destino turístico essencialmente propício para a realização do ecoturismo. Iniciativas diversas buscam a implementação do turismo de base sustentável desde o início da realização de atividades turísticas no Arquipélago, tais como a criação das Unidades de Conservação Federias pelo Instituto Brasileiro do Meio Ambiente e Recursos Naturais Renováveis (IBAMA), e as ações do Instituto Chico Mendes de Conservação de Biodiversidade (ICMBio) e Projeto golfinho Rotador, dentre outros.

A criação de normas e regulamentos de uso e manejo, aliada ao processo de cadastramento dos condutores de ecoturismo do Parque Nacional Marinho constituem importantes iniciativas para o desenvolvimento do turismo sustentável de base local no arquipélago.

Em Fernando de Noronha, a observação da flora e da fauna é uma das mais importantes atividades realizadas pelos turistas. Por possuírem comportamentos que favorecem a fácil visualização pelos visitantes, os golfinhos rotadores são um dos polos dessas atividades. A observação dos golfinhos pode ser realizada em mirantes localizados em trilhas da ilha principal e em passeios de barco, ambos acompanhados de condutores locais. O turista tem acesso às informações quanto à biologia dos animais e a conservação ambiental, enquanto entra em contato com a natureza e com os atrativos paisagísticos locais.

Neste aspecto, o papel do condutor se torna evidente e essencial. Uma boa formação destes profissionais garante a base necessária para que o turismo desenvolva-se com uma finalidade educativa e ao mesmo tempo contribua para a conservação da localidade. Além disso, a formação profissional também possibilita a geração de emprego e renda para jovens e adultos moradores da região, sendo este um dos elementos do turismo sustentável.

Para atuar como condutor de ecoturismo nas áreas do Parque Nacional Marinho de Fernando de Noronha é exigido o credenciamento pelo ICMBio dos profissionais que atuam neste segmento. O pré-requisito para 0 referido credenciamento é a participação e aprovação dos condutores em cursos de capacitação profissional.

A investigação sobre as características e influências dos cursos de formação de condutores de ecoturismo em Fernando de Noronha torna-se relevante tanto por possibilitar a ampliação do conhecimento científico sobre a eficácia dessas iniciativas, como também fornecerá subsídios para os gestores públicos aperfeiçoarem o processo de qualificação profissional dos atuantes nessa área.

Nos últimos dez anos foram oferecidos diferentes cursos para os habitantes locais que atuam como condutores de ecoturismo em Fernando de Noronha, associados ao processo de credenciamento, sendo de forma sistemática os cursos promovidos pelo Projeto Golfinho Rotador.

Diante do exposto, pretendeu-se saber: Quais as características dos cursos de formação profissional de condutores de ecoturismo que foram 
oferecidos até o momento em Fernando de Noronha? Qual a influência desses cursos na atuação dos condutores no arquipélago de Fernando de Noronha? Qual a percepção dos turistas sobre o desempenho destes condutores?

Partindo-se desses problemas, o presente estudo teve como objetivo geral verificaras características e a influência dos cursos de capacitação profissional de condutores de ecoturismo em Fernando de Noronha pelo Projeto Golfinho Rotador na atuação destes profissionais. Para tal fim, foram estabelecidos os seguintes objetivos específicos: a) caracterizar os cursos de formação profissional de condutores de ecoturismo oferecidos em Fernando de Noronha; b) identificar o perfil sócio econômico dos condutores de ecoturismo em Fernando de Noronha;c) verificar a influência dos cursos de capacitação profissional na atuação dos condutores no Arquipélago;d) identificar as percepções dos turistas sobre a atuação dos condutores em Fernando de Noronha.

$\mathrm{Na}$ construção do embasamento teórico foram utilizados diversos autores como Dias (2005), Neiman (2007), Ruschmann (1997), Silva Júnior (2010) e Pinto (2008), dentre outros, que estudaram sobre o ecoturismo, o turismo de observação de golfinhos e a formação de guias e condutores, sendo assim dividido em cinco aspectos: ecoturismo, formação profissional em turismo e ecoturismo, condução em ecoturismo, ecoturismo em unidades de conservação: parque nacional marinho de Fernando de Noronha, e turismo de observação de cetáceos em Fernando de Noronha: uma alternativa para o ecoturismo.

\section{Área de estudo}

Localizado a $345 \mathrm{~km}$ de Natal (RN, Brasil), o arquipélago de Fernando de Noronha é protegido pela criação de unidades de conservação (UC), sendo composto por uma ilha principal e 17 ilhas secundárias, totalizando uma área de $26 \mathrm{~km}^{2}$ e maiores distancias de $10 \mathrm{~km}$ por 2,0 a 3,3 km de largura. A ilha principal, com 17,6 km², forma duas faces: a noroeste, que é denominada de mar de dentro e fica protegida dos ventos predominantes; do lado oposto há o chamado mar de fora, sendo este voltado para o mar aberto, mais agitado, com penhascos e maiorias das praias rochosas (SILVA Jr., 2010).

\section{Ecoturismo}

O turismo contemporâneo tem uma intensa relação com a natureza que é foco de interesse de pessoas que o utilizam como forma de escape ou compensação à vida nos centros urbanos. Sua construção ocorre em consequência da busca pelo verde e da fuga dos tumultos da sociedade moderna por pessoas que buscam utilizar seus tempos livres em contato com os ambientes naturais a fim de recuperar o equilíbrio psicofísico (NEIMAN; MENDONÇA; SCHLINDWEIN, 2008; RUSHMANN, 1997).

É certo que o ser humano sempre sentiu prazer no contato com belezas naturais. Porém isso era conseguido com mínimo esforço e não havia a preocupação em proteger a natureza que parecia infinita e os 
impactos produzidos pelo homem e suas tecnologias ainda eram reduzidos (KINKER, 2002).A relação entre meio ambiente natural e o turismo se torna bastante conflituosa à medida que há degradação ambiental por menor que seja o impacto no ambiente (PRADO et al, 2004).

Quando a atividade turística começou a emergir como um dos principais setores socioeconômicos mundiais entre as décadas de 1950 e 1970 (OMT, 2003), seu sucesso não estava atrelado a nenhum tipo de preocupação com o meio ambiente, pois a sua lucratividade era muito mais importante (SILVA, 2007). A atividade turística, como um todo, se desenvolveu com as características de fenômeno de massas em decorrência da Revolução industrial iniciada na Inglaterra no século XVIII (DIAS, 2005).

O turismo sustentável surge nas últimas décadas como uma excelente forma de crescimento da atividade turística, na medida em que propõe o desenvolvimento econômico atrelado à preservação do ambiente natural e ao equilíbrio social (PRADO et al, 2004; KINKER, 2002).

O turismo é fundamental como promotor de encontros de culturas, propulsor de interações e fluxos de ideias que conferem identidades a pessoas e lugares, em que há uma expectativa quanto ao local a ser visitado, suas particularidades e diversidades a serem oferecidas e a serem sentidas (NEIMAN; MENDONÇA; SCHLINDWEIN, 2008). No entanto, têmse constatado que na quase totalidade de destinos turísticos tem havido uma falta de cultura turística dos visitantes, que tendem a encarar seu tempo livre como sagrado, não dando assim a importância necessária para a conservação, por se julgarem insuficientes para serem responsabilizados pelas agressões a um determinado lugar em virtude do pouco tempo de permanência (RUSHMANN,1997).

Com os impactos gerados pela atividade, a visão acerca da natureza mudou drasticamente nas últimas décadas, e a necessidade de conservação levou a criação das primeiras Unidades de Conservação, segundo Raimundo (2008). E outras formas de turismo estão sendo propostas, recebendo as denominações de alternativos, responsável, ecológico e etc., sendo a natureza uma das bases destas atividades (RUSHMANN, 1997).

O Turismo de Natureza pode ser segmentado em alguns outros tipos de atividades como o turismo de aventura e o ecoturismo que envolve qualquer atividade desenvolvida na natureza, compreendendo assim um turismo ecológico. $O$ ecoturismo surge com a finalidade de solucionar problemas e melhorar a relação do turismo com o meio ambiente.

Enquanto alguns autores descrevem ecoturismo e turismo ecológico como sinônimos, outros definem o turismo ecológico como um passeio ao meio visitado, em que o turista entra em contato com a natureza e troca experiências como meio, enquanto para EMBRATUR o ecoturismo é definido como:

Um segmento da atividade turística que utiliza, de forma sustentável, o patrimônio natural e cultural, incentiva sua conservação e busca a formação de uma consciência ambientalista por meio da interpretação doambiente, promovendo o bem-estar das populações (BRASIL, 2008, p. 16). 
Quando surgiu o turismo ecológico, suas definições estavam atreladas apenas ao contato com o meio ambiente, através de quaisquer atividades que buscassem este fim. Já o ecoturismo pode ser entendido como uma evolução deste, pois busca a realização de tais atividades englobando a ideia de preservação da natureza, integração com a comunidade e educação ambiental. Desta maneira, compreende-se que o visitante que realiza uma atividade ecológica, não se caracteriza necessariamente como um ecoturista.

Budowski (1976) escreveu o primeiro artigo com finalidade de integrar turismo e conservação, mas a palavra ecoturismo foi introduzida no Brasil no final dos anos 1980 como uma proposta de contemplação e conservação da natureza, seguindo a tendência mundial de valorização do meio ambiente e como reação aos impactos negativos causados pelo turismo de massa em ambientes naturais (BRASIL, 2008; KINKER, 2002). O IBAMA vem incentivando a prática do ecoturismo através da criação de novas unidades de conservação (UC), principalmente os Parques Nacionais (COSTA, 2002).

O segmento do ecoturismo possibilita a valorização e preservação do patrimônio, viabilizando retornos econômicos, proporcionando uma educação ambiental, através da conscientização da importância da preservação do meio ambiente e gerando benefícios diretos para comunidade (PINTO, 2008).

Rodrigues (2003) apresenta ecoturismo como sendo uma atividade econômica de baixo impacto ambiental que ocorre em áreas de significativo valor natural e cultural, contribuindo para a conservação da biodiversidade e sociodiversidade através de atividades educativas e recreacionais, ao mesmo tempo em que beneficia as comunidades receptoras. Esse segmento tende a contribuir para um desenvolvimento turístico sustentável.

\section{Formação profissional em turismo e ecoturismo}

A formação profissional, diante das constantes evoluções do mercado de trabalho no século $X X I$, tem se tornado cada vez mais presente. $O$ conhecimento aliado às qualificações específicas tem se tornado um prérequisito para muitas áreas, e a necessidade de constante aperfeiçoamento é observada na atuação profissional diante das frequentes mudanças neste mercado.

O conceito de emprego vem sendo substituído pelo trabalho e a atividade produtiva dependendo cada vez mais do conhecimento.O trabalhador necessita ser criativo, crítico e pensante, estando preparado para adaptar-se rapidamente às constantes mudanças e exigências do mercado e da sociedade (SILVA; CUNHA, 2002). Diante desta nova forma de enxergar o profissional, as instituições de ensino demonstram uma preocupação com o perfil desejado quando da elaboração de seus cursos e grades curriculares.

Em relação ao mercado de trabalho e a formação profissional, vê-se uma necessidade de mudança na educação a fim de solucionar os problemas e carências enfrentados pela sociedade. Esse objetivo imposto 
está relacionado não somente a formação de bons profissionais, mas também de um novo individuo, dando maior valor a personalidade e poder de pensar e decidir de cada um (SHIGUNOV; MACIEL, 2002).

Quando se trata da atividade turística, os cursos superiores possuem a responsabilidade de preparar o profissional para as condições dinâmicas do mercado, e aquelas instituições que insistirem em seguir os padrões e paradigmas tradicionais tendem a não obter sucesso por formarem pessoas com competências ultrapassadas e que não atendem as exigências do mercado atual (DEGRAZIA, 2005).

A segmentação turística tem demandado a criação de cursos de formações especificas direcionados as diversas áreas de atuação. A formação profissional na área de ecoturismo está associada à formação de guias nos diversos âmbitos (locais, regionais, nacional etc.) e condutores locais, como também está inserido como disciplina nos cursos de formação superior em Turismo.

A educação ambiental e a interpretação ambiental, como premissas das atividades ecoturísticas, necessitam além do contato com o meio ambiente, de um profissional bem capacitado, que possa transformar o ambiente visitado, através de conhecimentos sobre o local e sobre a preservação e conservação da natureza.

Com a crescente demanda ecoturística, novos tipos de formação profissional estão surgindo em outras categorias, como é o caso dos guias e condutores turísticos, que levam as informações para os turistas acerca do patrimônio natural e cultural. Quando a atividade é classificada ou inserida no ecoturismo, esta formação ganha especificidades e o profissional deve seguir certos princípios de conservação ambiental aliada a educação ambiental.

\section{Condução em ecoturismo}

O ecoturismo é o segmento do turismo que, através da conscientização da importância da preservação do meio ambiente, possibilita valorizar e preservar o patrimônio, viabilizando retornos econômicos, proporcionando a educação ambiental e gerando benefícios para a comunidade local (PINTO, 2008).

O contato direto com o meio ambiente leva a uma reflexão acerca da ideia de paisagem (RODRIGUES, 2003). Neiman (2007) afirma que a concepção do Ecoturismo como um turismo de destino - a natureza deveria ser substituída por uma forma de fazer turismo e o papel do condutor não é resumido a levar, mas sim a fazer e perceber.

A condução em ecoturismo surge para atender a esse principio educativo e a demanda crescente de ecoturistas, e o profissional desta área exerce o papel de repassar as informações do local visitado ajudando na educação ambiental e proporcionando ao individuo a interpretação ambiental, de modo a ajudar na conscientização e conservação do meio ambiente. 
Ser guia vai muito além de ser um mero acompanhante ou orientador, necessita ser um artista que sabe conferir cor e calor a uma paisagem, um mágico que é capaz de dar vida a pedras milenares, um acompanhante que torna os maiores deslocamentos curtos trajetos, um profissional, em definitivo, que é capaz de nos fazer sentir em nossas próprias casas enquanto estamos no interior de arranha-céu hoteleiro ou em uma cabana africana (PICAZO apud CHIMENTI, 2007).

Os guias e condutores servem de elo entre o ecoturista e o meio ambiente, sendo elementos de extrema importância para uma mudança de atitude em relação ao ambiente visitado e a contratação destes profissionais é mais uma maneira de geração de renda para as comunidade locais que vivem da atividade turística (CRONEMBERGER, 2007).

A atuação e classificação destes profissionais foram modificadas de acordo com as especificidades e características do país, da localidade, dos atrativos e da estrutura turística que é desenvolvida (CHIMENTI, 2007). Uma boa formação garante à atividade turística a base necessária para que se desenvolva com uma finalidade ecológica ao mesmo tempo em que ajude na conservação.

No Brasil em 1985 a EMBRATUR criou o Projeto Turismo Ecológico com o intuito de dar inicio ao ordenamento do segmento, e na mesma década foram autorizados os primeiro cursos de guias especializados (BRASIL, 2008).

É importante diferenciar as duas categorias na condução de atividades turísticas.Guia de turismo é o profissional cadastrado pela EMBRATUR e regulamentado pela lei $n$ 8.623, de 28 de janeiro de 1993, ao qual é atribuída a função de acompanhar, orientar e transmitir informações em excursões, podendo ser classificado de acordo com formação especifica podendo atuar em âmbito estadual, nacional, internacional, etc. (SENNA; ADORNO; MAGALHÃES, 2008; CRONEMBERGER, 2007).

Já a atividade de condutor de turismo, também chamado de monitor ambiental, não é uma profissão regulamentada por lei, não havendo uma forma legal de entrar para o mercado.Esses profissionais costumam ser cadastrados em agências oficiais de turismo do estado ou localidade, com atuação apenas local e comumente em Unidades de Conservação, e costumando passar por cursos de capacitação financiados por organizações não governamentais ou iniciativas públicas. Para que um condutor possa se tornar um guia de turismo atuante em todos os estados, ele necessita realizar um dos cursos oferecidos pelas instituições autorizadas pela EMBRATUR (SENNA; ADORNO; MAGALHÃES, 2008; CRONEMBERGER, 2007; PINTO, 2008).

A instrução normativa ICMBIO $\mathrm{n}^{\circ} 8$, de 18 de setembro de 2008, considera como condutor de visitantes a pessoa cadastrada pelo órgão gestor da unidade de conservação, que tenha recebido a capacitação específica, sendo responsável pela condução em segurança de grupos aos locais permitidos, desenvolvendo atividades interpretativas sobre o ambiente natural e cultural visitado, e contribuindo para o monitoramento dos impactos socioambientais nos sítios de visitação. 
No Arquipélago de Fernando de Noronha são desenvolvidas diversas atividades com finalidades ecoturísticas, e tendo como foco a educação ambiental, esse tipo de turismo tende a ocorrer na companhia de um guia ou condutor que, para atingir a finalidade proposta pelo segmento, precisa ter conhecimento sobre a região apresentada e noções sobre meio ambiente e conservação.

A partir de 2010 o Parque Nacional Marinho de Fernando de Noronha iniciou o processo de credenciamento dos Condutores de ecoturismo para atuarem na referida Unidade de Conservação. Este processo exigiu a participação e aprovação dos interessados em cursos específicos de capacitação. O Projeto Golfinho Rotador já oferecia cursos com esse propósito desde o início dos anos 2000.

\title{
Ecoturismo em Unidades de Conservação: Parque Nacional Marinho de Fernando de Noronha
}

A principal estratégia proposta para a conservação e uso sustentável do meio ambiente é a criação de áreas protegidas, por meio das quais a biodiversidade, cultura e belezas naturais são conservadas e utilizadas sustentavelmente, mediante um suporte cientifico. A nível mundial o termo MPA's (Marine Protected Areas) é largamente utilizado, no contexto brasileiro o termo utilizado é Unidade de Conservação (UC).

Unidade de conservação diz respeito a toda área protegida que possui regulamentação própria de uso e manejo e que promove a preservação do meio ambiente de acordo com a categoria em que se enquadre (SCHENINI,2004).A unidade de conservação é o

\begin{abstract}
Espaço territorial e seus recursos ambientais, incluindo as águas jurisdicionais, com características naturais relevantes, legalmente instituído pelo Poder Público, com objetivos de conservação e limites definidos, sob regime especial de administração, ao qual se aplicam garantias adequadas de proteção (BRASIL, 2000).
\end{abstract}

A primeira área protegida foi registrada em 1872 nos Estados Unidos com a criação do Parque Nacional de Yellowstone, mostrando a preocupação em relação a conservação, surgindo assim as primeiras pretensões em legalizar áreas protegidas para resguardar ecossistemas e paisagens naturais (SCHENINI, 2004).

É calculado que em média um terço da biodiversidade mundial esteja concentrado nos territórios mais bem conservados e ecossistemas únicos brasileiros, como a mata atlântica, cerrado, floresta amazônica, ambientes marinhos, dentre outros (KINKER, 2002). E o Brasil preocupa-se cada vez mais com suas riquezas naturais, e cônscio de suas responsabilidades, está criando leis de proteção e conservação da natureza (SZKLAROWSKY, 2001). 
Com a criação do código florestal brasileiro de 1934, surgiu a primeira área protegida, o Parque Nacional de Itatiaia, no Rio de Janeiro (SCHENINI, 2004). Outro documento de significativa importância na defesa do meio ambiente e do patrimônio cultural foi à constituição de 1988, que busca através da conscientização brasileira, melhores condições de vida com a preservação da natureza (SZKLAROWSKY, 2001).

O IBAMA surgiu como parte de uma grande reestruturação para organização governamental das instituições ambientais (RYLANDS; BRANDON, 2013), e após anos de estudo e propostas junto ao congresso nacional, é promulgada a Lei no 9.985 de 18 de julho de 2000, referente a criação do Sistema Nacional de Unidades de Conservação da Natureza, auxiliando no ordenamento das leis dispostas acerca das categorias de manejo, e criando critérios e normas de gestão de áreas protegidas federais, estaduais ou municipais (SCHENINI, 2004).

Atualmente existem 54 Parques Nacionais no Brasil compreendendo uma área aproximada de 17.493.010 hectares (RYLANDS; BRANDON, 2013). Em conformidade com o Capítulo III art. 11, da referida Lei $n^{\circ} 9.985$ de 18 de julho de 2000,

O Parque Nacional tem como objetivo básico a preservação de ecossistemas naturais de grande relevância ecológica e beleza cênica, possibilitando a realização de pesquisas científicas e o desenvolvimento de atividades de educação e interpretação ambiental, de recreação em contato com a natureza e de turismo ecológico (PERNAMBUCO, 2008).

A visitação a esses espaços é permitida mediante as normas e restrições estabelecidas no plano de manejo, e as atividades ecoturísticas estão sendo estimuladas pelo governo federal por se tratarem de recursos para gerar renda para os Parques através de taxas de visitação e concessões de serviços, e contribuído com as regiões ao seu redor, que abrigam a infraestrutura receptiva (KINKER, 2002).

Para manejo da visitação às áreas protegidas, além de conhecer o recurso, é necessário conhecer as características e necessidades daqueles que o utilizam, sendo a infraestrutura para recepção do turista uma peça fundamental para realização do ecoturismo (KINKER, 2002). Para Pedrini et al. (2008), o ecoturismo brasileiro vem ocorrendo essencialmente nas unidades de conservação, por serem locais privilegiados para esse tipo de atividade.

Fernando de Noronha é o topo emerso de uma cadeia de montanhas submarinas de origem vulcânica entre o meio do oceano e o Brasil, sendo este composto por recifes de corais e com uma elevada biodiversidade marinha, que chama a atenção de pesquisadores e turistas (LINSKER, 2003).

O arquipélago é dividido em duas UC's Federais do Instituto Brasileiro do Meio Ambiente e dos Recursos Naturais Renováveis (IBAMA): A Área de Proteção Ambiental de Fernando de Noronha (APA-FN), que é uma UC de 
Uso Sustentável, onde é permitida a ocupação permanente de moradia, agropecuária, hotéis, prestação de serviços e instalações de infraestrutura; eo Parque Nacional Marinho de Fernando de Noronha (PARNAMAR-FN), que é uma UC de Proteção integral que compreende aproximadamente 50\% da área da Ilha de Fernando de Noronha, todas as demais 17 ilhas secundárias do Arquipélago e a maior parte das águas adjacentes até a profundidade de 50 metros, compreendendo um total de $112,7 \mathrm{~km}^{2}$ e $70 \%$ do Arquipélago (SILVA JR., 2010; SILVA JR., 2003; TISCHER, 2011).

O número de turistas e a população residente na llha de Fernando de Noronha se multiplicaram bastante em virtude do aumento da demanda pelo ecoturismo em unidades de conservação e das belezas cênica naturais do Arquipélago, além da divulgação junto à mídia nacional e internacional. Antes da criação do Parque Nacional Marinho de Fernando de Noronha, em 1988, a atividade turística no Arquipélago era pequena. No ano de 1992 foram contabilizados 10.094 turistas, enquanto que em 2002 verificou-se um aumento de $520 \%$ tendo o Arquipélago recebido 62.551 visitantes. A população residente na ilha também aumentou significativamente de 1988 a 2002, passando de 1500 para 3200 (SILVA JR, 2003).

Fernando de Noronha vem sofrendo com o crescimento do turismo e do número de moradores na ilha que surgem para ocupar os postos de serviços gerados pela atividade, apesar da Legislação que protege as duas unidades. A criação do Parque Nacional resguarda a maior parte do Arquipélago e garante $o$ enfoque ecológico na atividade turística e equipamentos implementados. $\mathrm{E}$ apesar dos impactos negativos do crescimento do turismo, o ecoturismo, com seu caráter educativo ambiental, funciona como um auxilio a conservação, ao mesmo tempo que é a principal fonte de renda dos ilhéus. Mas é necessário para o cumprimento dos objetivos propostos pelo PARNAMAR-FN, a implementação de novas medidas de manejo, visitação orientada por condutores capacitados e ampla distribuição de informações, de modo que todas essas propostas sejam subsidiadas por monitoramento ambiental (SILVA JR. 2003).

As organizações não governamentais (ONGs) que atuam com formulação de diretrizes e estratégias, monitoramento, implementação de programas e projetos de desenvolvimento sustentável alicerçados no turismo, entre outros, possuem um papel fundamental, na medida em que servem, muitas vezes, de facilitador entre o governo e comunidade, ajudando na gestão e conservação do meio ambiente. Em territórios insulares oceânicos, em que os efeitos das mudanças climáticas são mais visíveis (um grande desafio para o milênio), em que é necessário um cuidado diferente do exercido em áreas continentais protegidas, torna-se imprescindível conhecer esta realidade para uma melhor atuação das ONGs ambientalistas (ESTIMA et al.; MARTINS, 2013).

Fernando de Noronha faz parte da Rede Mundial de Reserva da Biosfera e dos Sítios de Patrimônio Mundial classificados pela UNESCO. Neste local, há a atuação de três ONGs ambientalistas que são a Fundação Centro Brasileiro de Proteção e Pesquisa das Tartarugas Marinhas (Fundação Pro-Tamar), com a pesquisa e conservação em trabalhos de campo e científicos, com a inclusão social através do apoio a cultura local e os cursos de capacitação e a educação ambiental junto a comunidade e aos 
turistas; o Centro Golfinho Rotador, com a pesquisa científica através do monitoramento dos golfinhos rotadores na Ilha, educação ambiental junto as crianças, e o desenvolvimento comunitário através das capacitações, palestras, entre outras; e o Instituto Ambiental de FN (IAFENO), que é uma organização não-governamental envolvida com as políticas locais (ESTIMA, ESTIMA et al., 2013).

\section{Metodologia}

Partindo-se do pressuposto de que toda pesquisa deve ser caracterizada quanto a aplicação, abordagem e objetivos, pode-se inferir que esta pesquisa caracteriza-se como descritiva, exploratória, aplicada, e de abordagem quali-quantitativa.

Em relação a abordagem, caracterizou-se como quali-quantitativa, pois ao mesmo tempo em que faz uso de recursos e técnicas estatísticas para quantificar dados, é descritiva quanto às informações coletada, fazendo uso de fontes primárias e secundárias de dados.

Quanto aos objetivos, ela é exploratória por se desenvolver pesquisa bibliográfica e estudos de caso a fim de desenvolver um referencial teórico que sirva de embasamento para a pesquisa, criando meios de comparar e melhor aplicar os dados; e descritiva, por fazer uso de coleta de dados e aplicação de questionários, a fim de descrever as características e influências dos cursos de capacitação profissional na atuação dos condutores de ecoturismo no Arquipélago e as percepções dos turistas sobre a atuação desses profissionais em Fernando de Noronha.

No que se refere à aplicação, pode-se inferir que esta pesquisa é considerada como aplicada, pois possui verdades e interesses locais, podendo ser utilizada na ampliação e melhoria dos cursos de formação de condutores de ecoturismo no Arquipélago de Fernando de Noronha, como na implantação de outras ações em prol da sustentabilidade no local.

Os sujeitos da pesquisa foram os condutores de ecoturismo cadastrados pelos órgãos gestores da atividade em Fernando de Noronha que realizem atividades com finalidades ecoturísticas e os turistas que utilizam os serviços destes profissionais durante sua estadia no local de estudo desta pesquisa.

A avaliação foi realizada no arquipélago, no período de 11 a 22 de junho de 2013 em uma amostra de 66 turistas que visitavam o arquipélago e 56 condutores de turismo que realizaram os cursos de Capacitação em Ecoturismo promovidos pelo Projeto Golfinho Rotador entre os anos de 2011 e 2013.

Foram aplicados dois tipos de questionários contendo em média 15 questões mesclando questões abertas, fechadas e o uso da escala Likert. $O$ uso deste tipo de escala foi considerado mais eficaz para este trabalho por permitir ao respondente avaliar um fenômeno (neste caso a eficácia dos cursos e a influência) mediante a uma escala de cinco alternativas em que não se havia respostas definitivas (como o sim e o não), mas sim afirmações autorreferentes em relação ao grau de concordância (GUNTHER, 2003). 
Os questionários foram entregues aos pesquisados juntamente com uma prancheta e uma caneta, e estes respondiam sempre na presença do pesquisador, sendo o primeiro aplicado aos condutores com questões acerca dos cursos profissionalizantes de formação de condutores oferecido pelo Projeto Golfinho Rotador em Fernando de Noronha, e o segundo foi aos turistas e possuía perguntas quanto à atuação dos condutores e a importância destes, ambos mesclando questões abertas e fechadas.

Os critérios adotados para determinação do universo da pesquisa foram as condições de acesso aos sujeitos da pesquisa e considerando o período de permanência no Arquipélago.

Com os dados obtidos foram procedidas análises descritivas, com elaboração de tabelas de frequência e fazendo uso de dois tipos de gráficos: de setores com frequência relativa para descrever o perfil socioeconômico dos entrevistados, e gráfico de colunas com frequência absoluta para melhor tratar os dados resultantes dos questionamentos.

\section{Análise e discussão dos resultados}

Os resultados foram organizados em três partes, sendo a primeira referente aos cursos de capacitação oferecidos pelo Projeto Golfinho Rotador, a segunda aos condutores e a influência dos cursos de formação profissional oferecidos na ilha e a terceira apresenta uma avaliação da atuação dos condutores através da experiência do turista que visita o Arquipélago de Fernando de Noronha.

\section{Cursos de capacitação oferecidos pelo Projeto Golfinho Rotador}

Segundo a instrução normativa ICMBio $n^{\circ} 8$, de 18 de setembro de 2008, é considerado condutor de visitantes a pessoa cadastrada pelo órgão gestor da unidade de conservação em questão e que tenha realizado algum curso de capacitação especifico, sendo responsável por conduzir os grupos de visitantes aos locais permitidos de forma segura, fazendo uso de atividades interpretativas sobre 0 ambiente $e$ contribuindo com 0 monitoramento dos impactos socioambientais.

As unidades de conservação são caracterizadas como locais que permitem visitação com trilhas guiadas ou autoguiadas por monitores nos espaços permitidos, que podem ser voluntários ou não. Quando o trabalho é realizado por voluntários havendo rotatividade destes, nem sempre é possível viabilizar uma capacitação bem elaborada acerca dos aspectos relevantes do ambiente, sendo estes responsáveis então por cuidar para que o visitante permaneça na trilha (MACHADO; RUSSO, 2008).

A instrução normativa $I C M B I O n^{\circ} 8$ rege como conteúdo mínimo desejável para os cursos de formação de condutores os itens listados abaixo e considera que estes temas devem ser abordados com ênfase em atividades práticas: 
-Tema I: Meio ambiente e cultura

Abordando acerca da história e geografia regional; ambiente da unidade de conservação em questão; turismo e sustentabilidade e a legislação pertinente.

-Tema II: Trabalho do condutor

Abordando acerca das técnicas de condução; atividades de interpretação ambiental; monitoramento de impactos; e ética, apresentação pessoal e relações interpessoais.

-Tema III: Segurança e equipamentos

Abordando acerca de primeiros socorros, resgate, combate a incêndios; e sexualidade, DST e drogas.

Seguindo o conteúdo proposto na instrução normativa citada acima, o curso de Condutor de Visitantes em Ecoturismo em Unidades de Conservação, promovido pelo Projeto Golfinho Rotador no arquipélago possui seu programa de aulas distribuídos em 7 momentos, sendo estes:

-1 Momento: Em sala de aula, aborda-se os conceitos básicos de turismo ede ecoturismo; ecoturismo, turismo de natureza, turismo de aventura e turismo de contemplação; ecoturismo em Noronha (Origem e desenvolvimento); e pontos potenciais para o ecoturismo em Noronha.

-2 ${ }^{\circ}$ Momento: Atividade de campo em que há visitação a um local escolhido pelo grupo para análise da prática do ecoturismo.

- $3^{\circ}$ Momento: Em sala de aula realiza-se a análise dos pontos fortes e fracos da localidade visitada e da atuação do grupo em relação ao local; ecoturismo e desenvolvimento sustentável, aspectos conceituais que permitem ao guia trabalhar o ecoturismo, elaboração de roteiros; Procedimentos para condução de visitantes (o papel do condutor).

-4 Momento: Atividade de campo em que são abordados conceitos de biodiversidade; conceitos de conservação ambiental; legislação ambiental de interesse ao turismo, unidades de conservação; e montagem de roteiros em grupo.

-5 $5^{\circ}$ e $6^{\circ}$ Momentos: Em campo, executam-se os roteiros elaborados pelos grupos.

-7 ${ }^{\circ}$ Momento: Em sala de aula é feita uma avaliação dos roteiros realizados e do curso.

Além deste curso de Condutor de Visitantes, o Projeto Golfinho Rotador já realizou entre os anos de 2011 e 2013 outros cursos direcionados a estes profissionais e a outros públicos totalizando 42 turmas, como segue na Tabela 1. 
Tabela 1: relação dos cursos de capacitação realizados pelo Projeto Golfinho Rotador no Arquipélago de Fernando de Noronha no período de 2011 a 2013.

Table 1: list of training courses conducted by the Projeto Golfinho Rotador in Fernando de Noronha Archipelago in the period from 2011 to 2013.

\begin{tabular}{|c|c|c|c|}
\hline $\begin{array}{l}\text { Períodos } \\
\text { (Anos) }\end{array}$ & $\begin{array}{c}\text { Quantidades } \\
\text { de Turmas }\end{array}$ & Cursos & Público \\
\hline $\begin{array}{c}2011,2012 \mathrm{e} \\
2013\end{array}$ & 12 & Conversação em inglês & $\begin{array}{c}\text { População em geral e } \\
\text { hospedarias }\end{array}$ \\
\hline 2012 e 2013 & 7 & Primeiros Socorros & $\begin{array}{l}\text { Condutores, barqueiros, } \\
\text { taxistas, ICMBio e demais } \\
\text { interessados }\end{array}$ \\
\hline 2012 e 2013 & 5 & Legislação Ambiental (aplicada) & $\begin{array}{l}\text { Condutores, ICMBIO, } \\
\text { barqueiros e taxistas }\end{array}$ \\
\hline 2012 & 2 & Unidades de Conservação & Condutores \\
\hline 2012 & 2 & Fauna de Fernando de Noronha & Condutores \\
\hline 2012 & 2 & Flora de Fernando de Noronha & Condutores \\
\hline 2012 & 2 & Condutor de Visitantes & Condutores \\
\hline 2012 & 2 & Geografia Regional & Condutores \\
\hline 2012 & 2 & Histórico/Cultural & Condutores \\
\hline 2012 & 2 & Ética & Condutores \\
\hline 2013 & $\overline{1}$ & Ecossistemas de FN & ICMBio \\
\hline 2013 & 1 & Ecossistemas Marinhos de FN & Barqueiros \\
\hline 2013 & 1 & Ecossistemas Terrestres de FN & Taxistas \\
\hline 2013 & 1 & Sustentabilidade & $\begin{array}{c}\text { População em geral e } \\
\text { hospedarias }\end{array}$ \\
\hline Total & 42 & & \\
\hline
\end{tabular}

Fonte: Projeto Golfinho Rotador (2013). Source: Projeto Golfinho Rotador (2013).

Para efetuar o cadastro como condutor de visitantes no Arquipélago é preciso ter feito os cursos de capacitação direcionados a estes profissionais. Há atualmente 285 condutores cadastrados em Fernando de Noronha segundo informações passadas pelo órgão gestor do PARNAMAR-FN.

\section{Condutores}

\section{Perfil Socioeconômico dos condutores}

Quanto ao perfil socioeconômico dos condutores, dos 56 entrevistados, $95 \%$ eram do sexo masculino e $5 \%$ do sexo feminino, o que nos permite observar que a maioria dos condutores atuantes na ilha são homens, pois a aplicação dos questionários ocorreu no período de trabalhos destes e nos locais onde havia maior concentração de condutores. No que se refere a faixa etária dos entrevistados foi verificado que estes possuíam de 19 e 59 anos de idade, visto que $59 \%$ dos entrevistados informou possuir idade entre 19 e 35 anos, $25 \%$ possuem de 36 a 45 anos e $16 \%$ de 46 a 59 anos. Nenhum dos entrevistados informou possuir idade inferior a 18 anos ou superior a 60 anos.

Resultado semelhante foi verificado no município do Parque Estadual do Jalapão, em que Senna, Adorno e Magalhães (2008) descrevem o perfil dos guias e condutores atuantes na região e comprovam que estes 
profissionais em sua maioria, possuem idade entre 15 e 40 anos e são predominantemente do sexo masculino (74\%).

Em relação à origem dos entrevistados, 52\% nasceram no Arquipélago de Fernando de Noronha - PE, 28\% eram de outras localidades do estado de Pernambuco, 9\% do estado do Rio Grande do Norte e 2\% do estado de São Paulo. Nove por cento dos que responderam ao questionário, não informou sua origem. Desta forma, é nítido que a maioria dos entrevistados atuantes na condução de visitantes são nativos da ilha. A média de tempo que os demais moram neste local é de 18,8 anos.

Quanto ao nível de escolaridade, foi observado que a maioria dos condutores que aceitaram responder os questionários haviam cursado até 0 ensino médio, o que corresponde a uma porcentagem de $61 \%$, enquanto $20 \%$ possuíam apenas o ensino fundamental e $14 \%$ onsino superior. Cinco por cento dos entrevistados não responderam ao questionamento. Pode-se então inferir que os profissionais atuantes nesta área em sua maioria possuem grau médio de escolaridade.

Quando questionados se já atuavam como condutores antes dos cursos de formação profissional oferecidos na ilha, $91 \%$ informou que sim e apenas $7 \%$ respondeu que não. Porém, alguns possuíam como principal fonte de renda outras atividades, e após a realização dos cursos, a condução de visitantes ganhou mais espaço.

O turismo na ilha de Fernando de Noronha está em constante evolução desde a criação do Parnamar-FN em consequência do aumento da demanda pelo ecoturismo em unidades de conservação, a beleza cênica natural e a grande divulgação do Arquipélago em âmbito nacional e internacional, aumentando assim o número de turistas e a população residente no local (SILVA JUNIOR, 2003).

No período que antecedeu a criação do Parque Nacional Marinho de Fernando de Noronha, por volta de 1988, a ilha contava com apenas cinco condutores de visitantes. Em 2003 existiam cerca de 50 condutores autorizados a percorrer as trilhas do Parque. Atualmente, para entrar na área do Parque os condutores devem ser cadastrados pelo órgão gestor, havendo 285 condutores cadastrados na ilha (SILVA JUNIOR, 2003).

Através de uma comparação tendo como foco a realização dos cursos, foi observado que antes destes, a principal fonte de renda dos entrevistados já era predominantemente o turismo (não especificando a atuação) e a condução turística. Verificou-se um aumento de 11 pontos percentuais do número de profissionais atuando como condutores de ecoturismo após a realização dos cursos do Projeto Golfinho Rotador (Figuras 1 e 2). 


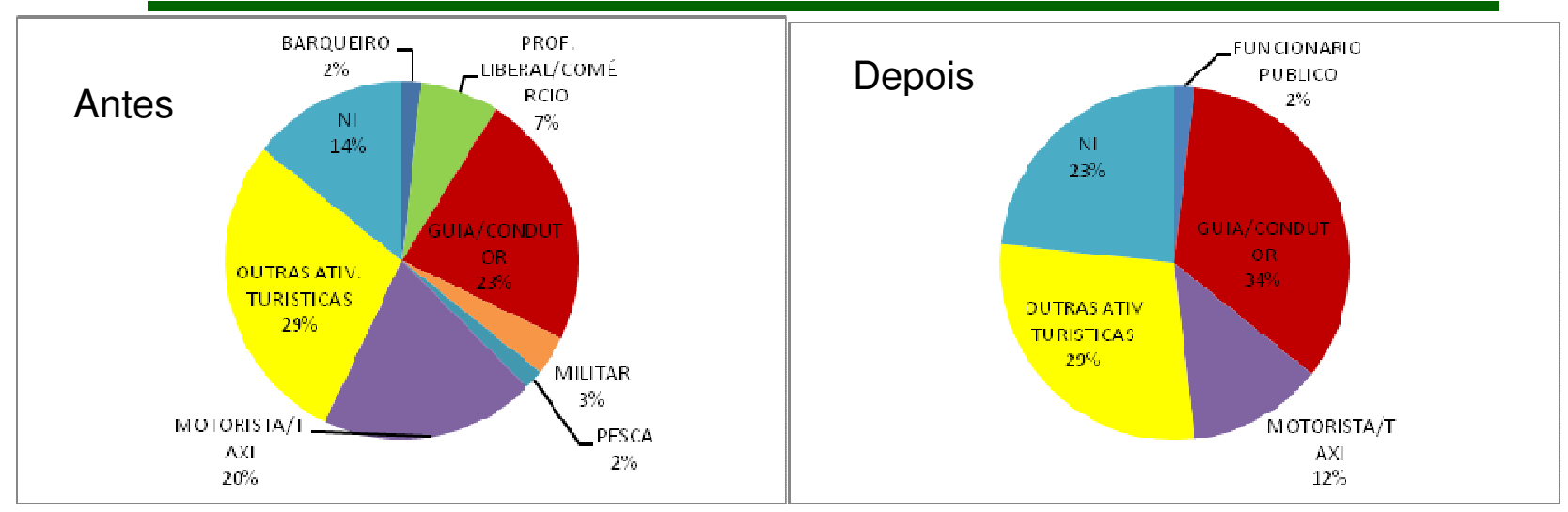

Figuras 1 e 2: Frequências relativas das principais fontes de renda dos condutores de ecoturismo entrevistados em Fernando de Noronha - PE antes e depois da realização dos cursos profissionalizantes oferecidos pelo Projeto Golfinho Rotador, no período de 11 a 22 de junho de 2013. $\mathrm{Nl}=\mathrm{Não}$ informado, PROF.= Profissional, ATIV.=Atividades.

Figures 1 and 2: Relative frequencies of the main sources of income from ecotourism drivers interviewed in Fernando de Noronha (PE, Brazil) before and after the completion of vocational courses offered by Projeto Golfinho Rotador, in the period 11-22 June 2013. NI = uniformed, PROF . = Professional , ATIV. = activities .

A renda recebida também obteve melhorias após a realização dos cursos, visto que antes da realização dos cursos $73 \%$ dos condutores que aceitou responder ao questionário informou receber de 2 a 5 salários mínimos, $13 \%$ de 6 a 9 salários mínimos e apenas $9 \%$ recebiam até 1 salário. Nos resultados referentes ao período após a realização do curso, a quantidade de condutores que recebiam de 2 a 5 salários caiu para $64 \%$, os de 6 a 9 aumentaram para $18 \%$ e os que recebiam até 1 salário diminuiu de 9 para 1\%. Dezesseis por cento dos entrevistados preferiu não responder quanto recebia após a realização dos cursos.

Desta forma, pode-se inferir que a formação profissional influenciou na renda familiar e na determinação da principal fonte de renda dos condutores de ecoturismo.

\section{Influência dos cursos na atuação dos condutores de ecoturismo}

Em relação à influência dos cursos de capacitação na atuação dos condutores que fizeram os cursos profissionalizantes oferecidos pelo Projeto Golfinho Rotador, quando questionados se os cursos forneceram conhecimentos suficientes para o bom exercício da atividade, das 56 pessoas que responderam aos questionários, 28 concordaram totalmente, 12 concordaram parcialmente e 10 nem concordaram, nem discordaram (Figura 3). Foi percebido que apenas 6 pessoas discordaram parcialmente $e$ nenhuma pessoa discordou totalmente, verificando-se então que os condutores capacitados se consideram aptos a boa realização da profissão com os conhecimentos adquiridos. 


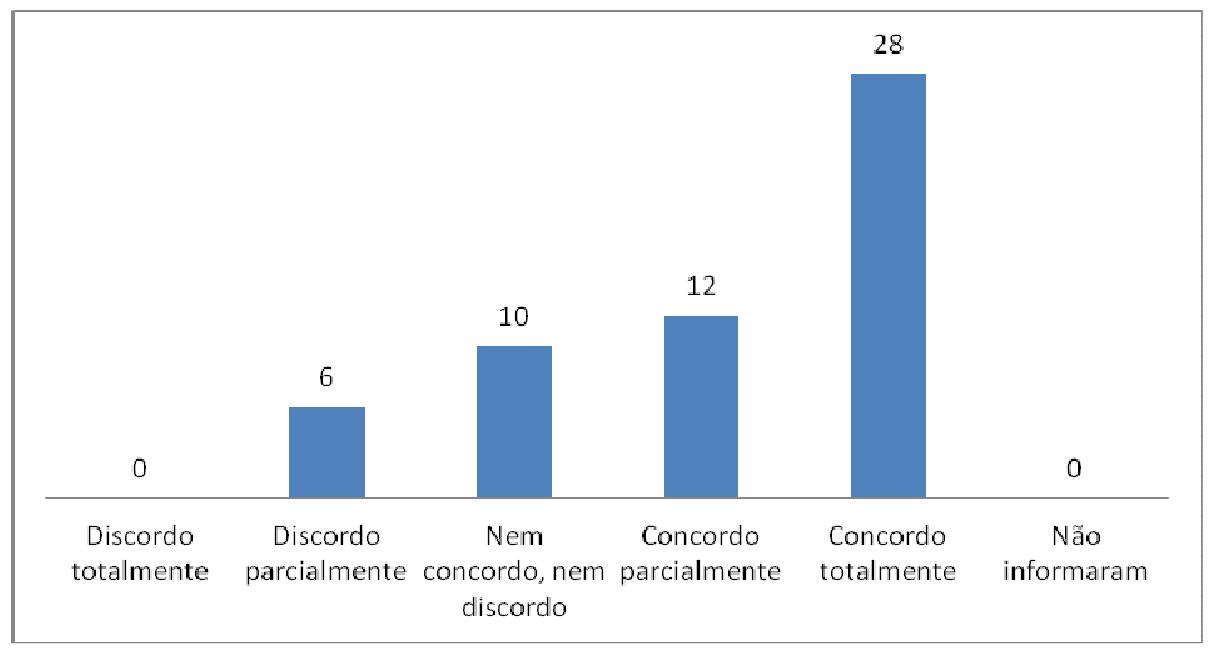

Figura 3: Frequência absoluta do grau de concordância dos condutores de ecoturismo entrevistados quando questionados se "O curso te forneceu conhecimentos suficientes para 0 bom exercício da atividade" como condutor de turismo em Fernando de Noronha, no período.

Figure 3: Absolute frequency of the degree of agreement of ecotourism respondents when asked drivers to "The course provided you sufficient knowledge for the proper exercise of the activity" as tourism driver in Fernando de Noronha in the period.

Com exceção de 1 entrevistado que discordou parcialmente e 4 que foram imparciais, todos os demais respondentes concordaram parcialmente e totalmente (15 e 36 pessoas, respectivamente) que o conteúdo abordado durante os cursos de formação de condutores serão úteis em sua atuação profissionais (Figura 4). Essa afirmação é reforçada mais adiante em outros questionamentos.

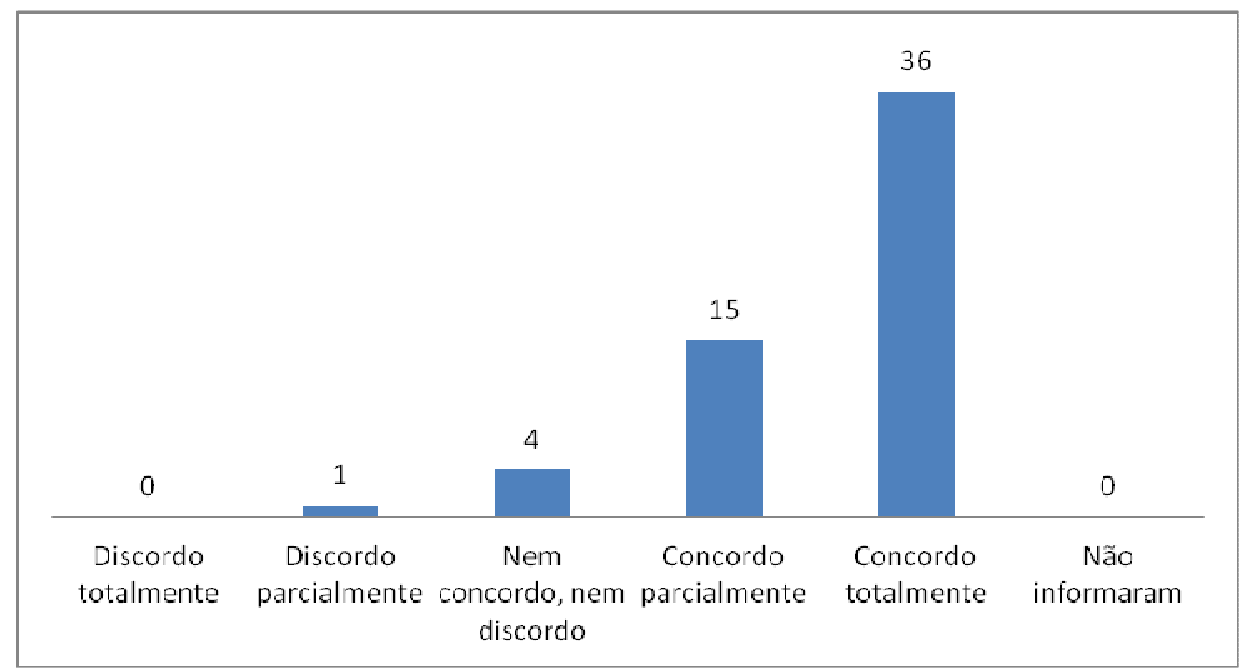

Figura 4: Frequência absoluta do grau de concordância dos condutores de ecoturismo entrevistados quando questionados se "acreditas que o conteúdo abordado durante os cursos de formação de condutores serão úteis em sua atuação profissionais" como condutor de turismo.

Figure 4: Absolute frequency of the degree of agreement of ecotourism drivers interviewed when asked if they "believe that the content covered during the driver training courses will be helpful in your professional performance" as tourism driver. 
Sabendo que os guias e condutores servem de elo entre o ecoturista e o meio ambiente, sendo elementos de relevante importância para uma mudança de atitude em relação ao ambiente visitado (CRONEMBERGER, 2007), os assuntos abordados nas aulas devem ter o máximo de proximidade com o que eles praticam no dia-a-dia como profissionais. A percepção positiva dos atuantes na área quanto à utilidade dos conteúdos durante a realização dos cursos de capacitação profissional realizados pelo Projeto Golfinho Rotador em Fernando de Noronha mostraram uma aproximação entre teoria e prática.

Da mesma forma, quando questionados se estão presenciando os assuntos vistos nas aulas, 30 pessoas responderam que concordam totalmente, 12 que concordam parcialmente e 8 nem concordaram, nem discordaram da afirmação (Figura 5). As demais respostas somaram 5 pessoas.

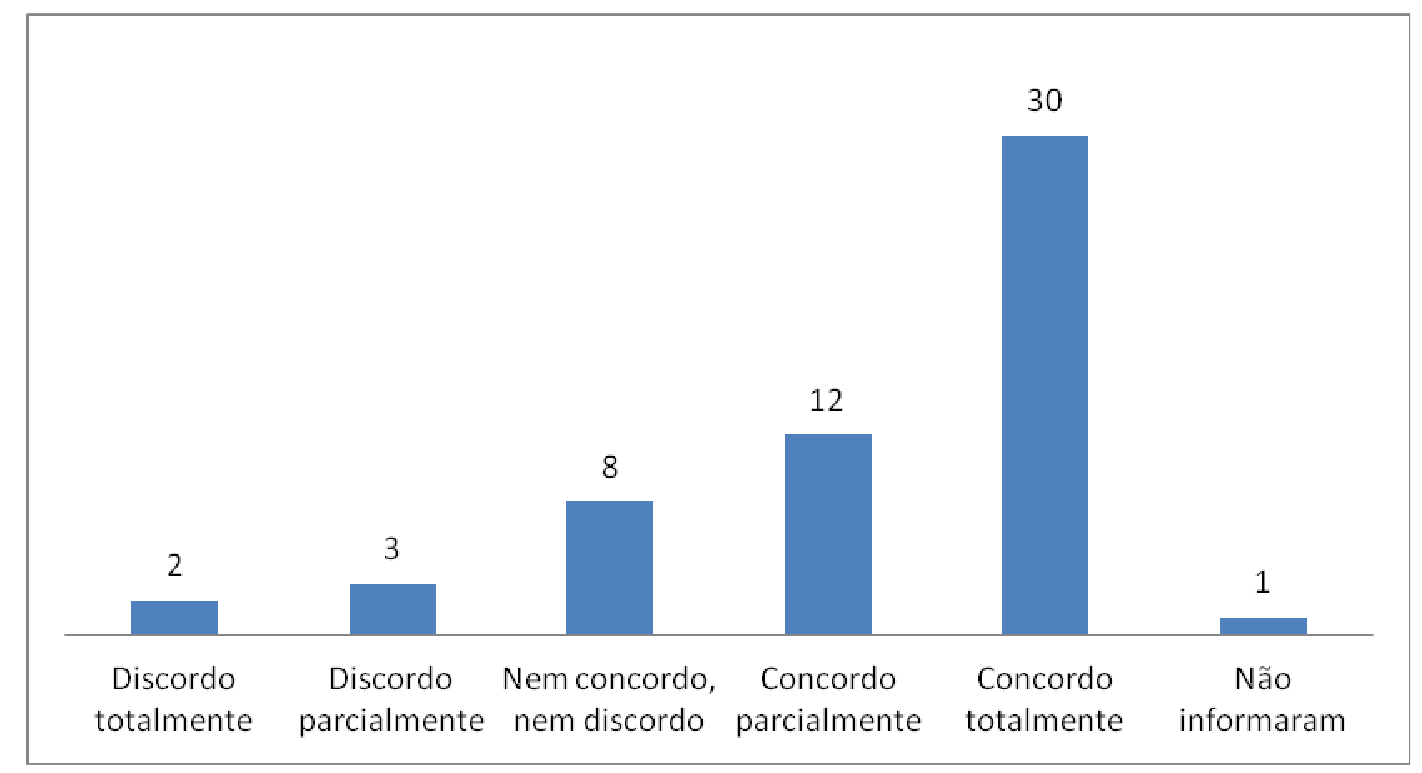

Figura 5: Frequência absoluta do grau de concordância dos condutores de ecoturismo entrevistados quando questionados se "Estais presenciando os assuntos vistos nas aulas" em Fernando de Noronha - PE, no período de 11 a 22 de junho de 2013.

Figure 5: Absolute frequency of the degree of agreement of ecotourism drivers interviewed when asked if "You are witnessing the visa issues in class" in Fernando de Noronha (PE, Brazil), in the period from 11 to 22 June 2013.

A prática dos assuntos aprendidos em sala também foi um dos questionamentos desta avaliação, e obteve resultado semelhante, pois 35 dos 56 entrevistados acreditam estar praticando o que aprenderam durante a realização dos cursos, 7 concordaram parcialmente e nenhum dos respondentes discordaram totalmente desta afirmação (Figura 6). Deste modo, podemos observar que há de fato uma similaridade entre os conteúdos passados com o cotidiano dos atuantes na área. 


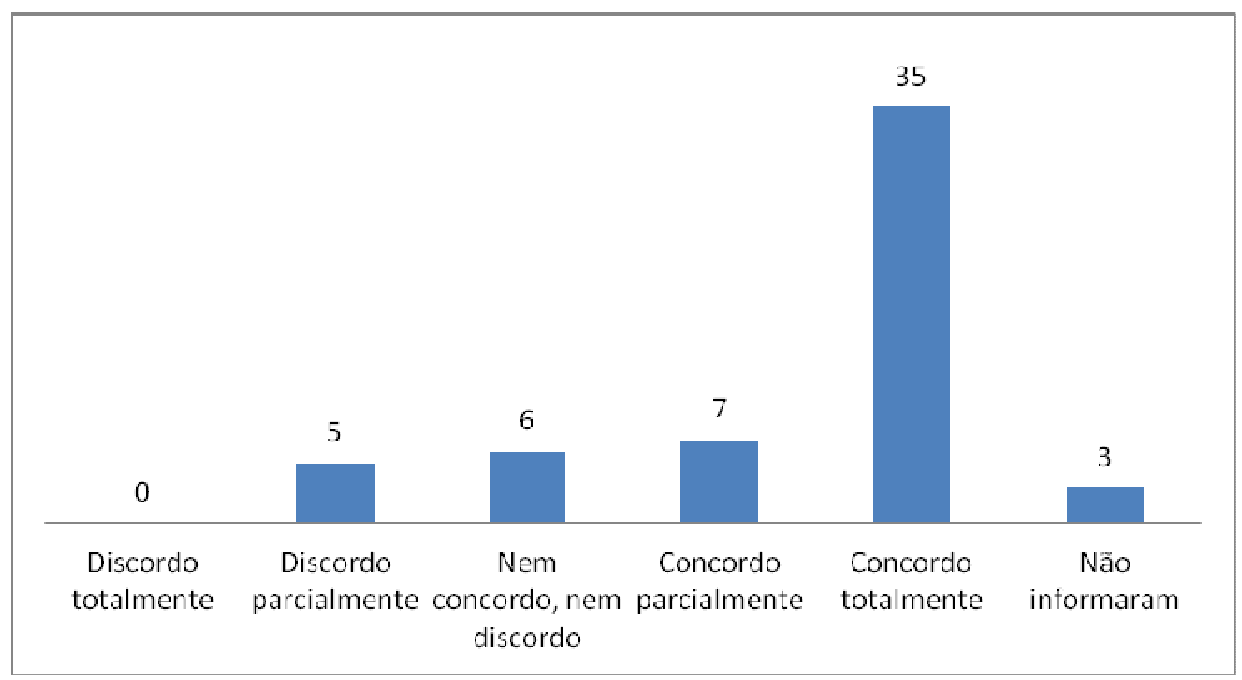

Figura 6: Frequência absoluta do grau de concordância dos condutores de ecoturismo entrevistados quando questionados se "Estais praticando os assuntos vistos nas aulas" em Fernando de Noronha - PE, no período de 11 a 22 de junho de 2013.

Figure 6: Absolute frequency of the degree of agreement of ecotourism drivers interviewed when asked if "You are practicing visa issues in class" in Fernando de Noronha (PE, Brazil), in the period from 11 to 22 June 2013.

Quanto ao comprometimento e reconhecimento profissional dos condutores de turismo que realizaram os cursos de formação de condutores oferecidos pelo Projeto Golfinho Rotador, verificou-se que dos 56 respondentes, 28 concordaram totalmente que os cursos trouxeram maior reconhecimento perante os turistas, agências e operadoras de turismo, 13 concordaram parcialmente e 8 nem discordaram e nem concordaram. Sabendo-se que o mercado de trabalho está cada vez mais competitivo, a qualificação profissional se torna um diferencial para os profissionais que conduzem turistas. Percebe-se que há um grande número de condutores de ecoturismo no Arquipélago de Fernando de Noronha que trabalham de forma autônoma, e há poucas agências e operadoras de turismo no local, o que possibilita uma melhor escolha dos funcionários a serem contratados.

No que se refere à contribuição dos condutores para o monitoramento e desenvolvimento sustentável da atividade, foram feitos dois questionamentos. Ao primeiro questionamento - Contribuis para 0 monitoramento dos impactos socioambientais nos sítios de visitação - foram verificados 33 concordantes totalmente e 12 parciais. $O$ segundo questionamento referente a contribuição exercida sobre desenvolvimento de turismo sustentável em FN apresentou resultados bastante semelhantes.

É importante que estes profissionais em suas formações recebam instruções para serem meios de contribuição do monitoramento nos sítios de visitação, visto que serão estes os responsáveis pelas informações passadas, e a atividade de ecoturismo exige uma consciência maior dos visitantes. Só assim poderá se desenvolver o turismo de forma sustentável.

Através do questionamento - Acredita que a formação profissional faz diferença na atuação do profissional que conduz turistas - foi percebido que 36 dos 56 respondentes concordaram totalmente, 11 concordaram 
parcialmente, e apenas 2 pessoas discordaram parcialmente (Figura 7). Percebe-se assim que os condutores são conscientes da importância de ter feito esta formação para a atuação na área de ecoturismo.

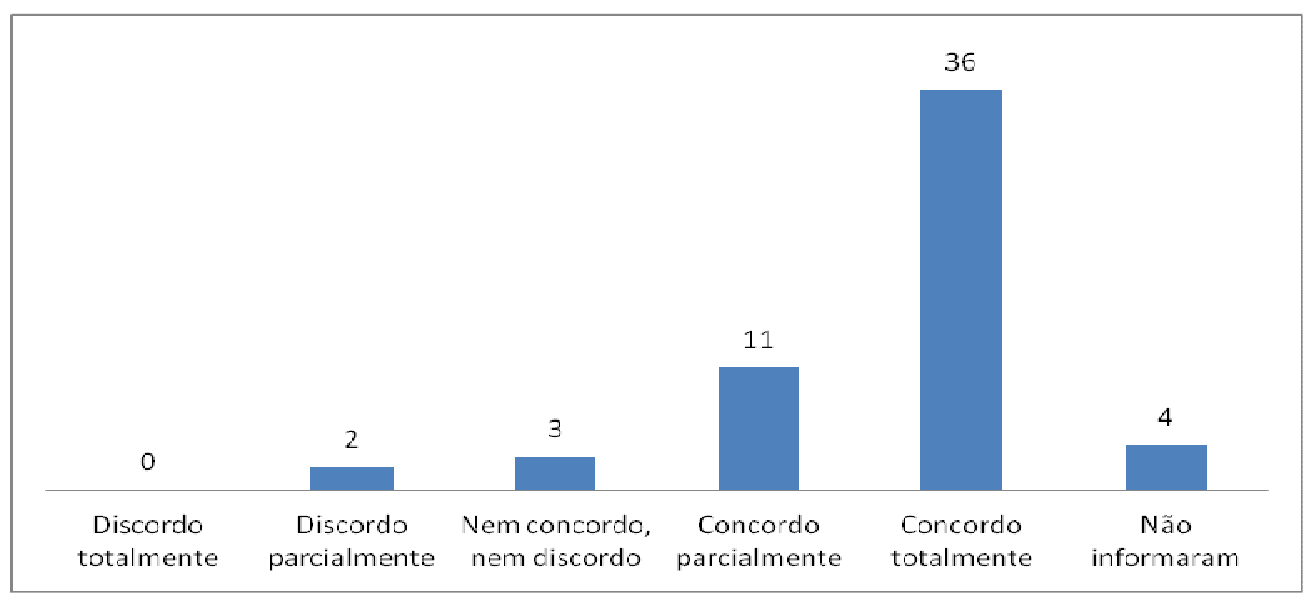

Figura 7: Frequência absoluta do grau de concordância dos condutores de ecoturismo entrevistados quando questionados se "Acredita que a formação profissional faz diferença na atuação do profissional que conduz turistas" como condutor de turismo em Fernando de Noronha - PE, no período de 11 a 22 de junho de 2013.

Figure 7: Absolute frequency of the degree of agreement of ecotourism drivers interviewed when asked if they "believed that training makes a difference in performance of the professional leading tourists" as tourism driver in Fernando de Noronha (PE, Brazil) in the period 11-22 June 2013.

Quanto à opinião dos entrevistados em relação à preferencia do mercado de trabalho por profissionais capacitados, 26 dos 56 condutores responderam concordar totalmente que os turistas, agências e operadoras de turismo dão preferência a este tipo de profissional. Doze respondentes ainda discordaram de tal afirmação (parcialmente ou totalmente) e 8 pessoas preferiram não concordar, nem discordar. Desta forma, observa-se que uma relevante parte dos condutores concorda que a preferencia do mercado está atrelada a formação de profissionais capacitados.

Quanto ao questionamento se os cursos oferecidos pelo Projeto Golfinho Rotador aumentaram as oportunidades do mercado de trabalho em Fernando de Noronha, 29 pessoas informaram concordar totalmente, 8 concordaram parcialmente, 7 nem discordaram e nem concordaram, 6 discordaram parcialmente e 6 discordaram totalmente. Este questionamento obteve resultado bastante semelhante ao anterior, o que nos permite afirmar que uma relevante parte dos condutores que realizaram os cursos de capacitação de condutores em Fernando de Noronha se consideram beneficiados diante das novas oportunidades surgidas após a realização dos cursos.

No que se refere à remuneração advinda do trabalho como condutor e se este é o suficiente para se viver bem em Fenando de Noronha, obtiveram-se resultados bem distribuídos, de modo que, dos 56 entrevistados, 13 discordaram totalmente, 12 concordaram parcialmente, 11 
concordaram totalmente, 11 preferiram ser imparciais nem concordando e nem discordando e 8 discordaram parcialmente.

Vale ressaltar que o custo de vida no Arquipélago de Fernando de Noronha é elevado. Portanto, apesar da melhoria na remuneração apresentada nos relatos acima e das oportunidades surgidas após a realização dos cursos, muitos dos condutores ainda consideram que não é suficiente apenas essa atividade para viver bem na localidade. Alguns ainda acumulam diversas funções ou dão prioridade a outras atividades, de modo a praticar a atividade de condução turística nas horas vagas ou apenas quando lhes é solicitado ou convém.

\section{Turistas}

Os dados a seguir são referentes à opinião dos turistas sobre os questionamentos que envolvem a atuação dos condutores bem como a importância da formação para esta atividade. Dos turistas entrevistados, $91 \%$ tiveram a companhia do condutor durante o passeio enquanto apenas $4 \%$ não. O que nos permitiu explorar melhor os dados acerca dos condutores.

Quanto ao condutor de turismo, dos 66 turistas entrevistados, 51 informaram concordar (39 totalmente e 12 parcialmente respectivamente) que foram abordadas informações suficientes acerca do local visitado, e 11 entrevistados preferiram não concordar e nem discordar. $E$ quanto ao questionamento referente à satisfação de informações abordadas pelos condutores sobre os golfinhos rotadores, 29 turistas concordaram totalmente, enquanto 9 concordaram parcialmente e 13 discordaram de tal afirmação, sendo 9 parcialmente e 4 totalmente. Assim é possível considerar que os condutores que realizaram os cursos de capacitação do Projeto Golfinho Rotador estão abordando de forma suficiente e satisfatória os conhecimentos sobre aspectos ambientais locais.

A importância de o condutor ter amplo conhecimento sobre uma localidade é devida as mudanças de prioridades dos turistas que tem buscado conhecer mais profundamente acerca da localidade visitada (BRAZ, MATTOS, 2007). Em se tratando de ecoturismo esta condição é potencializada, uma vez que o condutor assume o papel de facilitar a percepção e interpretação do local visitado.

Quando questionados se a presença de um condutor na realização de passeios tem influência positiva na realização de atividades turísticas em Fernando de Noronha, 52 turistas expressaram concordância, sendo que destes 40 concordaram totalmente, mostrando assim a elevada importância deste profissional para as atividades de ecoturismo na opinião dos visitantes.

O condutor de turismo desempenha um papel de relevante importância nas atividades ecoturísticas. Através do reconhecimento destes trabalhadores perante os turistas pode-se verificar que as atividades de condução estão sendo bem executadas em Fernando de Noronha.

No que se refere ao domínio das informações abordadas pelo condutor, 42 pessoas informaram concordar totalmente que o condutor 
demonstrou domínio e 12 pessoas preferiram ser imparciais. Apenas 1 pessoa discordou totalmente de tal afirmação. Observa-se assim que os condutores atuantes na área possuem informações suficientes acerca da localidade.

Quando questionados se sentiram inibidos diante da presença do condutor, 42 respondentes discordaram totalmente, além dos 5 outros que discordaram parcialmente, mostrando assim que este não é um aparente problema. Esta afirmação é fortalecida no questionamento que segue.

Para o questionamento - Me senti mais seguro diante de possíveis eventualidades por estar na companhia do condutor - 42 turistas responderam concordar totalmente. Desta forma, verificou-se que os condutores transmitem mais segurança ao turista, podendo ser este um dos pontos cruciais na hora de se optar por estes profissionais na escolha de um destino ou elaboração de um pacote.

A segurança foi um ponto bastante mencionado pelos entrevistados, sendo esta referente não somente a possíveis perigos que poderiam ocorrer, mas também a segurança diante de eventualidade, dos locais visitados, sua flora e fauna.

Quanto à formação de condutores, foi observado que 56 dos 66 entrevistados concordaram totalmente com a seguinte afirmação: Acredito que a formação de condutores tem influência positiva no desempenho destes profissionais (Figura 8).

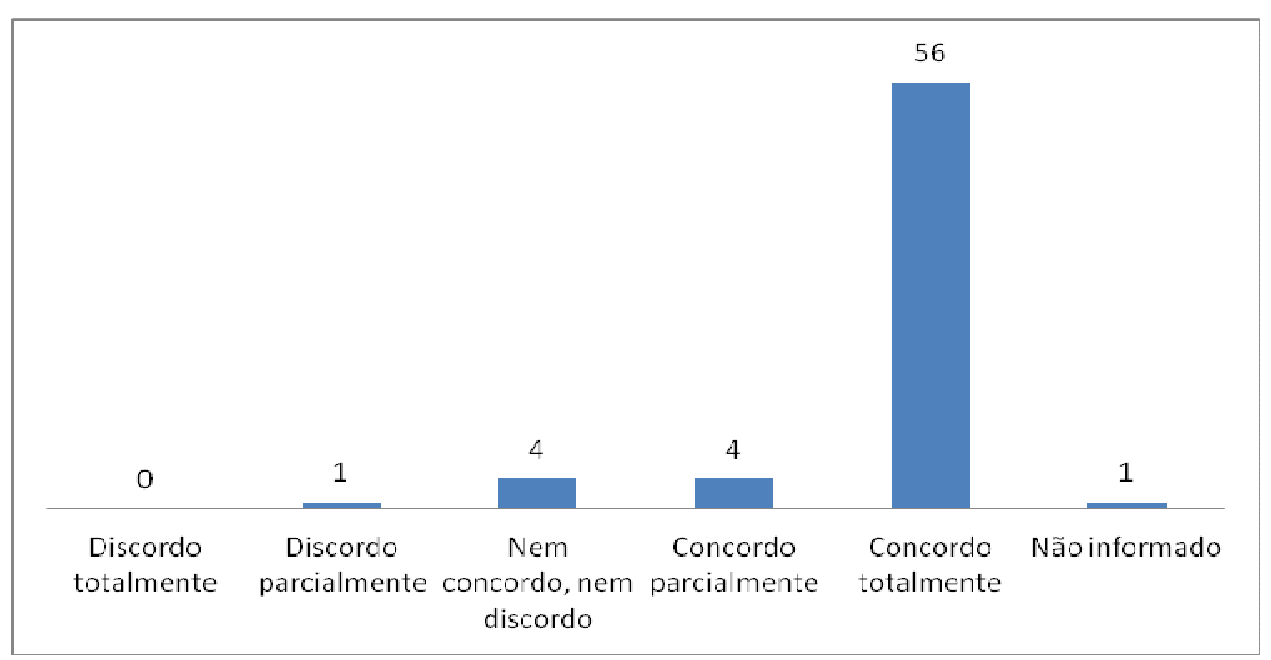

Figura 8: Frequência absoluta da resposta dos turistas entrevistados quando questionados "Acredito que a formação de condutores/guias faz toda a diferença no desempenho destes profissionais", em Fernando de Noronha - PE, no período de 11 a 22 de junho de 2013.

Figure 8: Absolute frequency of the tourists interviewed response when asked "I believe that the training of drivers / guides makes all the difference in performance of these professionals" in Fernando de Noronha (PE, Brazil), in the period from 11 to 22 June 2013.

Desta forma verificamos a relevância da formação profissional dos condutores na opinião dos turistas. A prática e os conhecimentos do local aliados ao conhecimento teórico fazem do desempenho do condutor 
capacitado muito mais eficaz, e diante do competitivo mercado de trabalho a relevância desta formação se faz mais presente, sendo esta um diferencial.

E a quase totalidade dos entrevistados concordaram totalmente que 0 condutor é essencial nas atividades ecoturisticas, sendo responsáveis por 58 dos 66 que aceitaram responder ao questionário, visto que apenas uma pessoa discordou parcialmente (Figura 9). Este resultado, assim como o do questionamento anterior, confirma que o turista tem consciência da importância destes profissionais para a atividade.

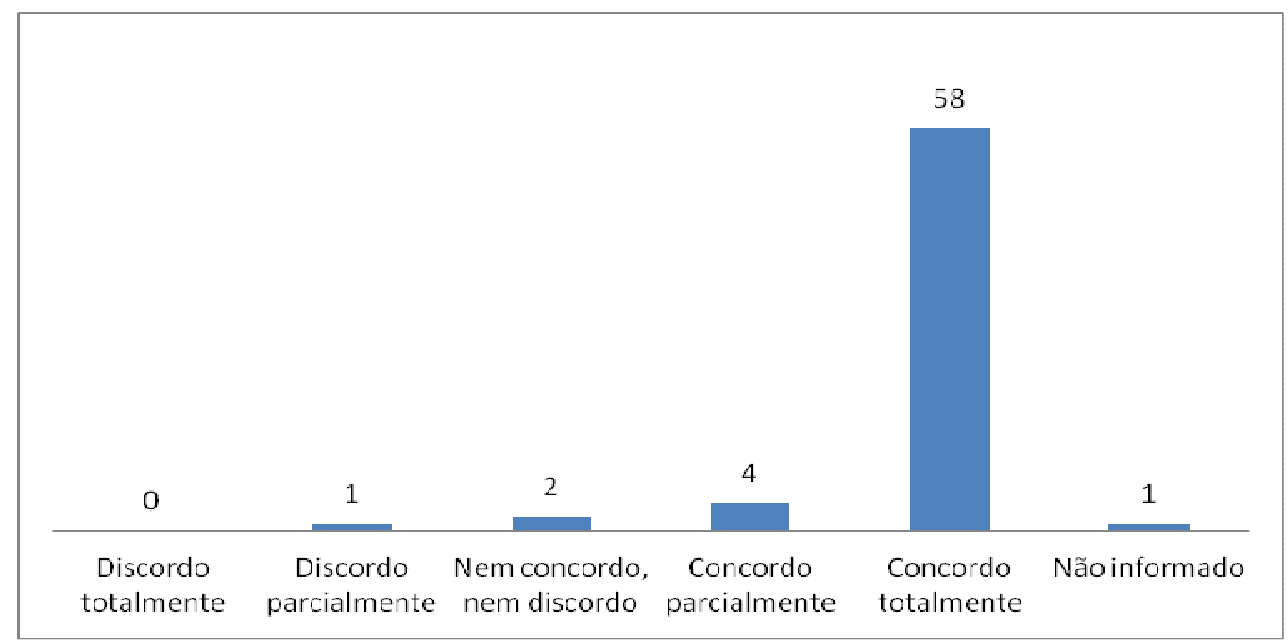

Figura 9: Frequência absoluta da resposta dos turistas entrevistados quando questionados "O condutor/guia é essencial nas atividades ecoturísticas", em Fernando de Noronha - PE, no período de 11 a 22 de junho de 2013.

Figure 9: Absolute frequency of the tourists interviewed response when asked "The driver / guide is essential in ecotourism activities" in Fernando de Noronha (PE, Brazil), in the period from 11 to 22 June 2013.

Ao questionar aos turistas quais as vantagens e desvantagens de se ter a companhia de um condutor/guia durante o passeio, foram observadas opiniões semelhantes, de modo que as informações trabalhadas e os novos conhecimentos adquiridos foram os pontos mais mencionados pelos entrevistados. A segurança do grupo foi outro quesito muito lembrado. Quanto ao passeio, a otimização do tempo e o direcionamento de melhores locais e o que deve ser observado foram outras vantagens mencionadas. $A$ preservação dos ecossistemas e a conscientização ambiental foram pouco lembradas dentre os respondentes ao questionário.

Poucas desvantagens foram indicadas, e alguns entrevistados ainda informaram não haver desvantagens em se ter a companhia de um condutor. Dessa forma, apenas foram indicadas como pontos negativos: a limitação de locais a serem visitados, o cumprimento de horários e a rapidez dos passeios. Foi sugerido ainda que o condutor fosse opcional no Parque Nacional, sendo uma fonte da obtenção de novos conhecimentos e não um controlador, sendo este importante apenas para os que não possuem a consciência ambiental. 


\section{Considerações finais}

Os cursos de capacitação profissional oferecidos aos condutores de ecoturismo pelo Projeto Golfinho Rotador no Arquipélago de Fernando de Noronha foram caracterizados como sendo eficientes, pois foram verificadas mudanças positivas na atuação profissional e melhoria de renda dos condutores. Além disso, considera-se que estes cursos foram importantes para o desenvolvimento do ecoturismo e sustentabilidade de Fernando de Noronha.

Os conteúdos dos cursos oferecidos também apresentaram abrangência, em comparação ao mínimo indicado na instrução normativa do ICMBio para formação de condutores de ecoturismo em Unidades de Conservação.

O perfil dos condutores de ecoturismo atuantes no Arquipélago de Fernando de Noronha é predominantemente de homens jovens com escolaridade média, sendo mais da metade dos entrevistados nativos da ilha e atuantes diretamente com o turismo em formas diversas, podendo acumular atividades para complementar a renda familiar.

Foi observado por meio dos profissionais que conduzem turistas nascidos no Arquipélago de Fernando de Noronha que há um elevado interesse da população em realizar os cursos de capacitação oferecidos pelo Projeto Golfinho Rotadora fim de se tornarem aptos a trabalhar com 0 turismo. Essa situação contribui para reduzir o crescimento artificial de Fernando de Noronha por meio de contratações de profissionais vindos de fora do Arquipélago.

Constatou-se uma melhoria na renda familiar dos condutores após a realização dos cursos de capacitação profissional. Dessa forma muitos destes conseguem perceber que a preferência do mercado é por profissionais capacitados e que os cursos possibilitaram o acesso de jovens e adultos neste mercado.

Os dados coletados demonstraram uma influência positiva dos cursos na atuação dos condutores, formando indivíduos aptos à realização das atividades e conscientes quanto à utilidade do conteúdo que aprenderam em sala em relação a prática que desenvolvem no cotidiano.

Os condutores mostraram entender a importância da formação profissional na atuação e informaram estar contribuindo para 0 monitoramento nos sítios de visitação e no desenvolvimento de um turismo sustentável no Arquipélago.

Foi verificado que nos passeios com finalidade de observação de golfinhos que ocorrem através de barcos e no mirante, e nos encontro ocorridos de outras formas, como por exemplo nos mergulhos rebocado e autônomo, os turistas se posicionaram favoráveis a importância de se ter um condutor para a realização do ecoturismo, mostrando satisfação e segurança por estar na companhia destes profissionais.

Fernando de Noronha, com suas belas paisagens e diversidade ambiental, tem um grande potencial para a realização de atividades 
ecoturísticas. A formação de condutores que atuam nas áreas do PARNAMARFN capacita-os para atuarem como um elo importante entre as informações trabalhadas e a interpretação ambiental, assim como para monitorarem os sítios de visitação, garantindo a conservação e desenvolvimento sustentável do Arquipélago.

\section{Referências bibliográficas}

BRASIL. Decreto-lei ${ }^{\circ}$ Lei 9.985 de 18 de julho de 2000. Lex: SNUC Sistema Nacional de Unidades de Conservação da Natureza. Brasília: Senado Federal, 2000.

BRASIL. MINISTÉRIO DO TURISMO. Ecoturismo: Orientações básicas. Brasília: Ministério do Turismo, 2008.

CHIMENTI, S; TAVARES, A. Guia de Turismo: O profissional e a profissão. São Paulo: Editora Senac São Paulo, 2007.

COSTA, P. C. Ecoturismo. São Paulo: Aleph, 2002.

CRONEMBERG, C. Uma análise da atividade de condução de visitantes no Parque Nacional da Serra dos Órgãos. In: Anais do VI CONGRESSO NACIONAL DE ECOTURISMO, - CONECOTUR, 6. Itatiaia: UFRJ, 2007.

DEGRAZIA, C. F. Construindo competências na formação profissional em turismo. Revista Global Tourism. v. 2, n. 1, p. 1-9, nov. 2005.

DIAS, R. Introdução ao turismo. São Paulo: Atlas, 2005.

ESTIMA, D. C. et al. A atuação das Organizações Não-Governamentais ambientalistas no turismo em ilhas: o caso de Fernando de Noronha (PE). Revista Brasileira de Ecoturismo, São Paulo, v.6, n.1, p.153-170, jan./abr. 2013.

GUNTHER, H., 2003, Planejamento de pesquisa nas ciências sociais:Como elaborar um questionário.Brasilia: UNB, 2003.

KINKLER, S.,Ecoturismo e Conservação da natureza em Parques Nacionais. Campinas: Papirus, 2002.

LINSKER, R. Arquipélago de Fernando de Noronha: o paraíso do vulcão. São Paulo: Terra Viagem Editora, 2003.

MACHADO, B., ROSSO, A. J. A possibilidade educativa no processo de visitação em unidades de conservação. In: Anais do VIII CONGRESSO NACIONAL DE EDUCAÇÃO, 8. Curitiba: Champagnat, 2008.

NEIMAN, Z. A educação ambiental através do contato dirigido com a natureza. 2007. São Paulo: Universidade de São Paulo, Instituto de Psicologia, USP, 2007. (Tese Doutorado em Psicologia Experimental).

NEIMAN, Z.; MENDONÇA, V.M.; SCHLINDWEIN, M.N. Eu e a Brisa: reflexões sobre a experiência da viagem no turismo. Revista Brasileira de Ecoturismo, São Paulo, v.1, n.1, p.114-135, 2008.

OMT. Organização Mundial Do Turismo. Guia de Desenvolvimento do Turismo Sustentável. São Paulo: Bookman. Organização Mundial do Turismo, Brasil, 2003. 
PERNAMBUCO (Estado). Instrução normativa ICMBIO no $\mathbf{8}$, de 18 de setembro de 2008. Lex: Condutores de Visitantes no Arquipélago de Fernando de Noronha. Fernando de Noronha: ICMBIO, 2008.

PINTO, A. J. Ecoturismo e formação socioambiental dos guias de turismo de Lençóis-Ba (Chapada Diamantina). Goiânia: Enciclopédia Biosfera N.05, Instituto Construir e Conhecer, 2008.

PRADO, M. V. P. et al. Turismo sustentável e capacidade de carga dos atrativos turísticos no município de Canindé do São Francisco/SE: Uma reflexão dos aspectos metodológicos. Indaiatuba: Anppas, 2004. 11 p. Acesso em: 20 jan. $2012 . \quad$ Disponível em: $<$ http://www.anppas.org.br/encontro anual/encontro2/GT/GT15/marta virginia.pdf>.

RODRIGUES, A. B., (org). Ecoturismo no Brasil: possibilidades e limites. São Paulo: Contexto, 2003.

RUSCHMANN, D. V. M. Turismo e planejamento sustentável: A proteção do meio ambiente. Campinas: Papirus, 1997.

RYLANDS, A. B.; BRANDON, K. Unidades de Conservação Brasileiras. [online], 2013. Acesso em: 05/02/2013.Disponível em: $<$ http://www.unifap.br/ppgbio/doc/06 rylands brandon.pdf>.

SENNA, M. L.; ADORNO, L. F.; MAGALHÃES, H. G. Ecoturismo: estudo de caso com - condutores de turismo e turistas na região do jalapão/TO.Olam: Ciência \& Tecnologia, Rio Claro, v. 8, n. 2, p.219, jan. 2008.

SHENINI, P. C., COSTA, A. M., CASARIN, V. W. Unidades de Conservação: Aspectos Históricos e sua Evolução. In: CONGRESSO BRASILEIRO DE CADASTRO TÉCNICO MULTIFINALITÁRIO - COBRAC. Florianópolis: UFSC, 2004.

SHIGUNOV NETO, A.; MACIEL, L. S. B. Formação Profissional nos cursos de turismo do Brasil: Algumas reflexões à Luz da LDB/96 e das Diretrizes Curriculares para os cursos de graduação. In: SHIGUNOV NETO, A.; MACIEL, L. S. B. (Orgs). Currículo e Formação Profissional nos cursos de Turismo. Campinas: Papirus, 2002.

SILVA JÚNIOR, J. M. Os golfinhos de Noronha. $1^{\circ}$ Edição. São Paulo: Bambu, 2010.

SILVA, E. L., CUNHA, M.V. A formação profissional no século XXI:desafios e dilemas. Cl. Inf., Brasília, v.31, p. 77-82, 2002.

SILVA, L. R. (Eco)turismo: Confusões semânticas e conceituais de uma segmentação. Anais do VI CONGRESSO NACIONAL DE ECOTURISMO. Itatiaia: UFRJ, 2007.

SILVA-JR., J. M. Parque Nacional Marinho de Fernando de Noronha: Uso Público, Importância Econômica e Proposta de Manejo. In: Anais do SIMPÓSIO DE ÁREAS PROTEGIDAS CONSERVAÇÃO NO ÂMBITO DO CONE SUL, 2.Pelotas: UCP, 2003.

SZKLAROWSKY, L. F. Lei 9985, de 2000 - SNUC - Sistema Nacional de Unidades de Conservação da Natureza. In: Âmbito Jurídico. Rio Grande, II, n. 5, maio 2001. Acesso em mar. 2013. Disponível em: $<$ http://www.ambitojuridico.com.br/site/index.php?n link=revista artigos leitura\& artigo $i d=1995>$. 
TISCHER, M.C. Ocupação de área e interações de golfinhos-rotadores (Stenella longirostris) com o turismo náutico no Arquipélago Fernando de Noronha/PE, Brasil. Natal: Universidade Federal do Rio Grande do Norte, 2011. (Dissertação de Mestrado em Psicologia).

\section{Agradecimentos}

Estudo realizado com Patrocínio da PETROBRAS, por meio do Programa Petrobras Socioambiental. Publicação integrante da Série Rede Biomar: Turismo Sustentável e Sensibilização Ambiental. Programa Petrobras Socioambiental. Pesquisa realizada com recursos do Conselho Federal Gestor do Fundo de Defesa de Direitos Difusos, Convênio 752672/2010. Conselho Nacional de Desenvolvimento Científico e Tecnológico (CNPq): Edital MCT/CNPq 14/2009 - Universal.Número do Processo: 481445/2009-9. Bolsa de Iniciação Científica, Cota PIBIC/CNPq/Universidade do Estado do Rio Grande do Norte 2012/2013. Instituto Chico Mendes de Conservação da Biodiversidade (ICMBio) por meio do Parque Nacional Marinho de Fernando de Noronha e Centro Nacional de Pesquisa e Conservação de Mamíferos Aquáticos (CMA).

Adriana Israel de Almeida Pereira: Universidade do Estado do Rio Grande do Norte, Natal, RN, Brasil.

E-mail: adrianaisraelap@gmail.com

Link para o currículo Lattes: http://lattes.cnpq.br/1928428859524029

Flávio José de Lima Silva: Projeto Golfinho Rotador. Centro Golfinho Rotrador. Fernando de Noronha, PE, Brasil.

E-mail: flaviogolfinho@yahoo.com.br

Link para o currículo Lattes: http://lattes.cnpq.br/1421802360229451

José Martins da Silva Junior: Centro Nacional de Pesquisa e Conservação de Mamíferos Aquáticos/Instituto Chico Mendes de Conservação da Biodiversidade, Fernando de Noronha, PE, Brasil.

E-mail: josemartinscma@gmail.com

Link para o currículo Lattes: http://lattes.cnpq.br/1133638779776273

Data de submissão: 25 de agosto de 2014

Data de recebimento de correções: 06 de novembro de 2014

Data do aceite: 06 de novembro de 2014

Avaliado anonimamente 